\title{
Repulsed by Violence: Disgust Sensitivity Buffers Trait, Behavioral, and Daily Aggression
}

\author{
Richard S. Pond, Jr., and C. Nathan DeWall \\ University of Kentucky
}

Timothy Deckman and Ian M. Bonser
University of Kentucky

\author{
Nathaniel M. Lambert \\ The Florida State University \\ Frank D. Fincham \\ The Florida State University
}

\begin{abstract}
Many models of aggression include negatively valenced emotions as common elicitors of aggressive behavior. Yet, the motivational direction of these emotions is not taken into account. The current work explored whether sensitivity to a negative emotion associated with behavioral avoidance— disgust—will predict lower levels of aggression. Five studies tested the hypothesis that disgust sensitivity predicts less aggression. In Study $1(N=92)$, disgust sensitivity predicted less trait physical and verbal aggression. In Study $2(N=268)$, participants high in disgust sensitivity were less likely to behave aggressively towards a stranger on a reaction-time task. In Study $3(N=51)$, disgust sensitivity was associated with less intimate partner violence inclinations. Study $4(N=247)$ replicated this effect longitudinally. In Study $5(N=166)$, each domain of disgust (i.e., moral, sexual, and pathogen disgust) had a buffering effect on daily aggression when daily experiences activated those specific domains. These results highlight the usefulness of considering the motivational direction of an emotion when examining its influence on aggression.
\end{abstract}

Keywords: disgust sensitivity, emotion, avoidance, aggression, individual differences

\begin{abstract}
Violence and aggression permeate human culture. People aggress for many reasons, including anger, narcissistic entitlement, and poor self-control (see Anderson \& Bushman, 2002, for a review). Yet, relatively little work has considered the possibility that certain negative emotions can be linked to lower levels of aggression. Aggression is an inherently approach-related behavior (Harmon-Jones, 2003; Harmon-Jones \& Peterson, 2008; Smits \& Kuppens, 2005). Therefore, negative emotions that are strongly associated with behavioral avoidance may drive people to refrain from aggressive behavior. The current research focuses on one trait that is linked to both negative affect and behavioral avoidanceindividual differences in disgust sensitivity-that should be associated with lower levels of aggression.
\end{abstract}

\section{Link Between Aversive Events, Anger, and Aggression}

Aggression, defined as any behavior designed to harm someone who is motivated to avoid that harm (Baron \& Richardson, 1994),

This article was published Online First June 27, 2011.

Richard S. Pond, Jr., C. Nathan DeWall, Timothy Deckman, and Ian M. Bonser, Department of Psychology, University of Kentucky; Nathaniel M. Lambert and Frank D. Fincham, Family Institute, The Florida State University.

This research was supported in part by grants from the National Science Foundation (BCS-1104118 to C. Nathan DeWall). The opinions and conclusions expressed herein are those of the authors and do not necessarily reflect the opinions of the National Science Foundation.

Correspondence concerning this article should be addressed to Richard S. Pond, Jr., Department of Psychology, University of Kentucky, Kastle Hall 0003, Lexington, KY 40506-0044. E-mail: ricky.pond@gmail.com is often associated with aversive or unpleasant events (for a review see Bushman \& Huesmann, 2010). For instance, aggressive behavior is linked to ego threat (Baumeister, Smart, \& Boden, 1996; Bushman \& Baumeister, 1998), social rejection (Buckley, Winkel, \& Leary, 2004; DeWall, Twenge, Gitter, \& Baumeister, 2009; Twenge, Baumeister, Tice, \& Stucke, 2001; Warburton, Williams, \& Cairns, 2006), bad moods (Berkowitz, 1990; Bushman, Baumeister, \& Phillips, 2001), uncomfortably hot temperatures (Anderson, Deuser, \& DeNeve, 1995; Bushman, Wang, \& Anderson, 2005; DeWall \& Bushman, 2009), and rank odors (Rotton, 1979).

According to Berkowitz's (1990) cognitive neoassociationistic model, frustrations, negative affect, aggressive cues, and aggressive behaviors are intimately linked. Aversive stimuli prompt adaptive fight and flight responses. Unpleasant situations activate negative emotions that, when paired with aggressive cues, increase the likelihood that people will respond impulsively and aggressively as opposed to escaping the situation. From this perspective, any negative state can increase aggression. In fact, Berkowitz (1983) noted that impulsive aggression must be preceded by a negative emotional state.

One negative emotional state that is often associated with aggression is anger (Berkowitz, 1983, 1990). Anger reduces inhibitions against violence and increases aggressive cognition and arousal (Anderson \& Bushman, 2002). Anger is analogous to the aggressive arousal and attack displayed in animals in response to provocation or a challenge over resources (Blanchard \& Blanchard, 1984, 2003). When people are angry, they are motivated to alleviate that anger by venting or lashing out at others (Bushman et al., 2001; Bushman, Baumeister, \& Stack, 1999). 
Recent evidence suggests that anger is linked with aggression because of its association with approach motivation (Carver \& Harmon-Jones, 2009; Harmon-Jones, 2003; Harmon-Jones, Harmon-Jones, Abramson, \& Peterson, 2009). Trait approach motivation is positively associated with both trait anger and behavioral aggression (Carver, 2004; Harmon-Jones, 2003). Angry facial expressions activate approach-oriented motor behaviors (Wilkowski \& Meier, 2010). As well, anger is related to approachrelated positive affect (Harmon-Jones et al., 2009). On the other hand, trait avoidance motivation is inversely related to behavioral aggression and the tendency to express anger outwardly (HarmonJones, 2003; Smits \& Kuppens, 2005).

The implication is that a negative emotional state is not a sufficient condition for aggression. Instead, the motivational direction of the emotion should match that of the behavior. Much prior work has focused on a link between an approach-related emotion (anger) and an approach-related behavior (aggression). The current work sought to show that individual differences in the experience of a negatively valenced emotional state could predict lower aggression if that emotion was associated with behavioral avoidance, because aggression is negatively associated with avoidance motivation (Harmon-Jones, 2003). One candidate emotion is disgust.

\section{The Behavioral Immune System}

Disgust is a fundamental emotion that confers a significant survival advantage for those who have the capacity to experience it. Throughout evolutionary history, infectious pathogens posed a recurring threat to survival and reproductive goals (Tooby, 1982). Selection pressures within our ancestral environments led to the evolution of an intricate immune system, ready to defend the body against bacterial or viral infection. Yet the immune system is costly in the resources that it consumes (Brown, 2003; Schaller \& Duncan, 2007). Additionally, the immune system cannot take action until pathogens have entered the body and are detected by the immune system. A more efficient way of combating disease is to avoid pathogens in the first place by being sensitive to disgust.

Selection pressures posed by infectious microbes led to the development of a defense system designed to promote the behavioral avoidance of disease carriers, referred to as the behavioral immune system (Schaller, 2006; Schaller \& Duncan, 2007). Disgust is an important component of such an immune system and likely developed out of selectively advantageous behaviors for avoiding food toxins (Rozin \& Fallon, 1987). Evolution co-opted the emotion of disgust as a means of avoiding other people who may be carrying communicable diseases (Kurzban \& Leary, 2001). Recent work supports the role of disgust as an elicitor of behavioral avoidance. For example, disease primes facilitate repulsive arm movements amongst participants looking at photographs of faces (Mortensen, Becker, Ackerman, Neuberg, \& Kenrick, 2010). And disgust sensitivity predicts visual avoidance during tasks in which participants view films that contain disgusting images (Olatunji, Haidt, McKay, \& David, 2008).

The behavioral immune system is oversensitive and overgeneralizes, as it is more costly to perceive a sick person as healthy than to perceive a healthy person as sickly (Schaller \& Duncan, 2007). Additionally, cultural forces create considerable variation, through social-learning processes, as to what constitutes a disgust elicitor and what does not, particularly in the interpersonal realm (Rozin, Haidt, \& McCauley, 2008). For instance, Americans are more likely to link feelings of disgust to actions that limit a person's rights or degrade a person's dignity (e.g., racism, senseless murder), whereas the Japanese are more likely to link feelings of disgust to actions that frustrate their integration into the social world (e.g., failure to live up to standards, being shamed; Haidt, Rozin, McCauley, \& Imada, 1997). As such, sensitivity to disgust plays a significant role in our social functioning, particularly when we encounter others who exhibit nonnormative social behavior.

Humans have a fundamental desire to seek out and connect with people who can offer us positive, lasting relationships (Baumeister \& Leary, 1995). As humans depend on others for food, shelter, and protection, it is necessary to avoid individuals who disrupt or harm our valuable social networks. Therefore, avoiding social transgressors, and others who exhibit nonnormative or antisocial behavior, is highly advantageous (Kurzban \& Leary, 2001).

Research supports the idea that the behavioral immune system is triggered not only by exposure to pathogens but also by nonnormative social behavior. For example, chronic disease worries increase ethnocentric attitudes, such that people are more likely to associate foreigners with danger and will want to exclude or avoid them (Faulkner, Schaller, Park, \& Duncan, 2004; Navarrete \& Fessler, 2006). On the other hand, disgust sensitivity is positively associated with in-group attraction (Navarrete \& Fessler, 2006). Perceived vulnerability to disease predicts negative attitudes towards and stigmatization of the physically disabled (Park, Faulkner, \& Schaller, 2003). Disgust sensitivity is also associated with an increased disapproval of homosexuals (Inbar, Pizarro, Knobe, \& Bloom, 2009). Various antisocial behaviors, such as unfair treatment, lying, and cheating, also elicit feelings of disgust (Chapman, Kim, Susskind, \& Anderson, 2009; Haidt, McCauley, \& Rozin, 1994; Jones \& Fitness, 2008).

Because disgust is a defensive emotion, people who are highly sensitive to it should be oriented towards avoidant or withdrawal types of behaviors (Olatunji et al., 2008). This orientation towards behavioral avoidance is in direct conflict with physical aggression, which is approach oriented (Carver, 2004; Harmon-Jones, 2003). Therefore, we predicted that disgust sensitivity would generally be associated with less physical aggression (Studies 1-4). Additionally, we predicted that specific disgust domains (i.e., moral, sexual, and pathogen disgust) would have a unique effect in buffering aggression when daily events occur that provoke those domains (Study 5).

This hypothesis is consistent with the general aggression model (GAM; Anderson \& Bushman, 2002; DeWall \& Anderson, 2011). The GAM proposes that aggression depends heavily on the knowledge structures that people develop. These knowledge structures are primed by situational cues and are linked with emotional states that increase or decrease aggression. They signal how a situation should be construed and how one should react to it. Because social-learning processes contribute significantly to what constitutes a disgust elicitor for different individuals (Rozin et al., 2008), knowledge structures associated with disgust should be activated when people encounter those triggers. People who are more sensitive to one domain of disgust should exhibit more avoidant-type behaviors when a situational trigger activates the knowledge structures of that domain. 


\section{The Present Research}

The present research tested the hypothesis that disgust sensitivity predicts less aggression. To provide converging evidence, we used different procedures across five studies. For example, aggression was measured with five different methods (trait aggression, administration of aversive noise blasts, pins inserted into a voodoo doll representing a romantic partner, self-reported physical aggression and approval of intimate partner violence, and daily selfreport of physical aggression). Studies 1, 2, 4, and 5 measured aggression towards strangers, and Studies 3 and 4 measured aggression towards romantic partners. To address directionality issues associated with cross-sectional designs, we implemented a longitudinal design in Study 4. Finally, in Study 5 we examined whether different domains of disgust had a unique effect in reducing aggression when daily events associated with those domains occurred.

\section{Study 1: Trait Disgust Sensitivity Predicts Less Trait Aggression}

Study 1 provided an initial test of the hypothesis that disgust sensitivity relates to lower aggression. Participants completed measures of disgust sensitivity and trait aggression. Because trait physical aggression is most strongly related to behavioral aggression (Giancola \& Parrott, 2008), we predicted that people who are the most sensitive to disgust would be the least physically aggressive. We did not expect significant associations between disgust sensitivity and trait anger or trait hostility. Last, we did not make specific predictions about the association between disgust sensitivity and verbal aggression.

\section{Method}

Participants. Participants were 92 undergraduates (82\% women) who participated for partial course credit.

\section{Measures.}

Disgust sensitivity. To assess disgust sensitivity, participants completed the Three Domains of Disgust Scale (Tybur, Lieberman, \& Griskevicius, 2009). The disgust scale is a 21-item measure in which participants rate how disgusting they find a series of situations on a scale ranging from 0 (not at all disgusting) to 6 (extremely disgusting). The disgust measure has three subscales. The Pathogen Disgust subscale measures disgust sensitivity towards microbes, bodily fluids, and pathogens (e.g., "Accidentally touching a person's bloody cut"; Cronbach's $\alpha=.80$ ). The Sexual Disgust subscale measures disgust sensitivity towards sexual activity (e.g., "Performing oral sex"; Cronbach's $\alpha=.83$ ). The Moral Disgust subscale measures disgust sensitivity towards violations of social norms and morality (e.g., "Stealing from a neighbor"; Cronbach's $\alpha=.82$ ). The items were summed to form a general composite measure of disgust sensitivity, with higher numbers equating to higher disgust sensitivity (Cronbach's $\alpha=.85)$.

Trait aggression. To assess aggressive personality, participants completed the 29-item Aggression Questionnaire (AQ; Buss \& Perry, 1992). The AQ includes four subscales: Trait Physical Aggression (e.g., "Given enough provocation today, I might hit another person"; Cronbach's $\alpha=.72$ ), Verbal Aggression (e.g.,
"When people annoy me, I may tell them what I think of them"; Cronbach's $\alpha=.79$ ), Trait Anger (e.g., "I sometimes feel like a powder keg ready to explode"; Cronbach's $\alpha=.69$ ), and Hostility (e.g., "I know that 'friends' talk about me behind my back"; Cronbach's $\alpha=.82$ ).

Procedure. Near the beginning of the semester, participants completed the disgust sensitivity measure as part of a mass screening session. Next, participants completed the AQ in a separate laboratory session. Finally, they received a debriefing.

\section{Results}

We predicted that disgust sensitivity would be associated with lower physical aggression, while being unrelated to trait anger and hostility. As expected, disgust sensitivity predicted less physical aggression, $\beta=-.32, t(90)=-3.19, p=.002$. Disgust sensitivity was unrelated to trait anger, $\beta=-.15, t(90)=-1.41, p=.16$, and marginally related to less trait hostility, $\beta=-.19, t(90)=-1.78$, $p=.08$. Last, disgust sensitivity predicted less verbal aggression, $\beta=-.35, t(90)=-3.49, p=.001$. Thus, participants higher in disgust sensitivity were lower in trait physical and verbal aggression.

We next explored the associations between the three disgust subscales and the aggression subscales. Moral Disgust correlated negatively with Physical Aggression, $r(90)=-.39, p<.0001$; Verbal Aggression, $r(90)=-.33, p=.001$; and Trait Hostility, $r(90)=-.24, p=.02$, but it was unrelated to Trait Anger, $r(90)=$ $-.13, p=.21$. Sexual Disgust correlated negatively with Physical Aggression, $r(90)=-.28, p=.007$, and Verbal Aggression, $r(90)=-.30, p=.004$, and was only marginally negatively related to Trait Anger, $r(90)=-.18, p=.10$, and Trait Hostility, $r(90)=$ $-.18, p=.09$. Pathogen Disgust was unrelated to Physical Aggression, $r(90)=-.01, p=.93$; Verbal Aggression, $r(90)=-.12$, $p=.24$; Trait Anger, $r(90)=-.002, p=.99$; and Trait Hostility, $r(90)=.03, p=.76$.

\section{Discussion}

The results of Study 1 suggest that those who are sensitive to disgust are also low in trait physical and verbal aggression. This relationship offers initial evidence that sensitivity to a negatively valenced emotion can be associated with less aggression-if it is associated with behavioral avoidance (Harmon-Jones, 2003; Mortensen et al., 2010; Olatunji et al., 2008). The effect of disgust sensitivity on trait aggression was most reliable for the Moral and Sexual Disgust subscales, which suggests that these two domains drove the effect of disgust sensitivity on aggression in Study 1. Though we used one of the most widely employed and validated trait aggression scales, it is possible that this relationship is an artifact of self-report and may not hold for actual behavioral aggression. To examine this possibility, we expand on the current study by using a laboratory measure of behavioral aggression in Study 2 .

\section{Study 2: Trait Disgust Sensitivity Predicts Less Behavioral Aggression}

Study 1 provided initial evidence that disgust sensitivity predicted lower aggression. We sought to replicate this effect in Study 
2 , with one modification. Specifically, we sought to demonstrate that disgust sensitivity is associated with lower levels of behavioral aggression. In Study 2, participants played a brief reaction-time game where they could administer aversive and prolonged blasts of noise to a stranger. Because behavioral aggression is an approach-related behavior (Harmon-Jones, 2003) and disgust sensitivity relates to behavioral avoidance (Mortensen et al., 2010; Olatunji et al., 2008), we expected to observe the strongest effect of disgust sensitivity on the type of aggression to cause the strongest behavioral avoidance: blasting a stranger with extremely intense blasts of noise. We did not expect a relationship between disgust sensitivity and unprovoked aggression, presumably because participants had not yet experienced a trigger that would motivate behaviorally avoidant behavior.

\section{Method}

Participants. Participants were 268 undergraduates (72\% women) who participated for partial course credit.

\section{Measures.}

Disgust sensitivity. As in Study 1, participants completed the Three Domains of Disgust Scale (Tybur et al., 2009; Cronbach's $\alpha$ s for moral, sexual, and pathogen disgust were .86, .86, and .80, respectively). The items were summed to form a general composite measure of disgust sensitivity, with higher numbers equating to higher disgust sensitivity (Cronbach's $\alpha=.87$ ). No participant from Study 1 participated in Study 2.

Procedure. Participants completed the disgust scale during a mass screening session at the beginning of the semester. Participants then arrived at the laboratory to participate in a study ostensibly about how personality and limitations on interactions influence behavior. After giving informed consent, participants were instructed that they would be paired with a same-sex partner with whom they would play a brief reaction-time game. The game was a modified version of the Taylor aggression paradigm (TAP; Taylor, 1967), in which participants administered blasts of white noise to, and received them from, their partner. Participants were told that they and their partner would have to press a button as fast as possible on each of 33 trials and that whoever was slower would receive a blast of white noise through a pair of headphones. Participants set the level of noise their partner would receive in advance between $60 \mathrm{~dB}$ (Level 1) and $105 \mathrm{~dB}$ (Level 10). A no-noise level (Level 0) was provided. Participants could also control how long their partner suffered by how long they set the noise duration, from $0 \mathrm{~s}$ to $5 \mathrm{~s}$. The participants, essentially, controlled a weapon that they could use against their partners. In reality, participants completed the reaction-time task against the computer, which was programmed to mimic another person's actions. Of the 33 trials, the participant won 16 (randomly determined). After completing the noise-blast game, participants were fully debriefed.

We chose the noise-aggression task as our dependent measure because the TAP and its modified versions are among the most widely used and well-accepted measures of behavioral aggression (Anderson \& Bushman, 1997; Giancola \& Chermack, 1998; Giancola \& Zeichner, 1995). Because disgust sensitivity should be negatively associated with aggression, due to its relation with behavioral avoidance (Mortensen et al., 2010; Olatunji et al., 2008), we expected the strongest effect between disgust sensitivity and extreme aggression. The extreme aggression dependent variable was how many times participants selected the highest levels of intensity (i.e., 9 or 10) for their partner across trials (Bushman, Ridge, Das, Key, \& Busath, 2007). Extreme aggression scores could range from 0 to 33 , depending on the number of trials that participants selected either a 9 or a 10 for their partner $(M=3.58$, $S D=5.36$ ). To assess unprovoked aggression, we standardized and summed intensity and duration levels from the first trial of the competitive reaction-time task (Bushman \& Baumeister, 1998; $M=0, S D=1.50)$. The unprovoked aggression measure enabled us to determine whether disgust sensitivity related to aggression before participants experienced any blasts of noise from their partner.

\section{Results}

We predicted that disgust sensitivity would relate to lower levels of extreme aggression. As expected, disgust sensitivity was negatively associated with extreme aggression on the noise-blast task, $\beta=-.15, t(266)=-2.53, p=.01$. Those higher in disgust sensitivity chose the highest levels of noise intensity less often than did those lower in disgust sensitivity.

We next explored the associations between the three disgust subscales and extreme aggression. Moral Disgust correlated negatively with extreme aggression on the noise-blast task, $r(266)=$ $-.15, p=.02$. Sexual Disgust also correlated negatively with extreme aggression, $r(266)=-.25, p<.0001$. Pathogen Disgust was unrelated to extreme aggression on the noise-blast task, $r(266)=.09, p=.14$.

To determine whether the relationship between disgust sensitivity and lower aggression was unique to extreme instances of aggression, we examined the association between disgust sensitivity and unprovoked aggression. As expected, disgust sensitivity was not associated with unprovoked aggression, $\beta=0.03$, $t(266)=0.46, p=.65$. Similarly, none of the three disgust subscales were associated with unprovoked aggression: Moral Disgust, $r(266)=.03, p=.67$; Sexual Disgust, $r(266)=.02, p=$ .70 ; and Pathogen Disgust, $r(266)=.01, p=.86$.

\section{Discussion}

Using a behavioral measure of aggression in the laboratory, we showed that those highest in disgust sensitivity were less likely to choose the most extreme levels of noise against their partners, compared with those lower in disgust sensitivity. As in Study 1, the effect of disgust sensitivity on behavioral aggression was most reliable for the Moral and Sexual Disgust subscales, which suggests that these two domains drove the effect of disgust sensitivity on aggression in Study 2. Disgust sensitivity was unrelated to unprovoked aggression, presumably because an avoidant urge had not been stimulated. Studies 1 and 2 provide converging evidence that people who are sensitive to disgust behave less violently than people who are not easily disgusted. People who are highly sensitive to disgust should be oriented more towards avoidant or withdrawal types of behaviors (Olatunji et al., 2008), which is in direct conflict with the motivational direction of aggression (Harmon-Jones, 2003). Therefore, disgust sensitivity should relate to lower aggression, regardless of whether the target of aggression is a stranger or an intimate partner. We expanded on Studies 1 and 
2 by measuring aggressive inclinations in the context of romantic relationships in Study 3.

\section{Study 3: Trait Disgust Sensitivity Predicts Less Intimate Partner Violence Inclinations}

Studies 1 and 2 offer converging support for the hypothesis that disgust sensitivity predicts less aggression. We sought to replicate and extend these findings in Study 3 following one modification. The previous studies focused on aggression towards strangers. In Study 3, we tested whether this effect replicated for aggressive inclinations towards one's intimate relationship partner. Because disgust sensitivity orients people towards avoidant behaviors, we expected that disgust sensitivity would influence aggressive inclinations similarly whether the target was a stranger or an intimate partner.

\section{Method}

Participants. Participants were 51 undergraduates (59\% women) who were involved in a romantic relationship. Participant relationship length was reported as 2 years or more $(41.7 \%)$, between 19 and 24 months (3.3\%), between 13 and 18 months (11.7\%), between 7 and 12 months $(21.7 \%)$, between 4 and 6 months (5\%), between 2 and 3 months (5\%), and less than 2 months $(11.7 \%)$. Participants received partial course credit in exchange for participation.

\section{Measures.}

Disgust sensitivity. As in Studies 1 and 2, participants completed the Three Domains of Disgust Scale (Tybur et al., 2009; Cronbach's $\alpha$ s for moral, sexual, and pathogen disgust were .83 , .84 , and .83 , respectively). The items were summed to form a general composite measure of disgust sensitivity, with higher numbers equating to higher disgust sensitivity (Cronbach's $\alpha=.88$ ).

Voodoo doll task. Participants were asked to inflict harm on a doll that represented their current romantic relationship partner. As this study was part of a larger investigation on relationship satisfaction and partner forgiveness, participants answered items related to negative partner behaviors (e.g., "My partner tends to give me the cold shoulder"). Participants were told that, because they had answered questions about negative topics, some of which included people close to them, they could release some of their negative energy by putting pins in a doll that represented their current romantic relationship partner. Previous research has demonstrated that the use of a voodoo doll can serve as a valid proxy for harmful and aggressive behavior (Denzler, Förster, \& Liberman, 2009; Pronin, Wegner, McCarthy, \& Rodriguez, 2006). For example, Pronin and colleagues have shown that, by sticking pins into a voodoo doll that represented a research confederate, participants believed that they were causing real harm to that confederate (i.e., giving him or her a headache). Recent research has validated this paradigm for measuring aggressive inclinations, demonstrating that the use of the voodoo doll correlates with physical and psychological aggression, physical assault against a relationship partner, as well as the tendency to blast a relationship partner with louder and more prolonged aversive noise during a competitive reaction-time task (DeWall et al., 2011). Hence, the voodoo doll task served as an ethically responsible proxy for aggressive inclinations. Because participants completed each measure in the current study online, they were shown pictures of voodoo dolls that represented their romantic partner rather than actually interacting with the voodoo doll in a laboratory setting. Participants selected the number of pins they would like to stick into the voodoo doll. Participants could select from zero to 51 pins $(M=2.52, S D=3.55)$. Higher numbers of pins inserted indicate higher levels of intimate partner violence inclinations.

Procedure. This study is part of a larger investigation on relationship satisfaction and partner forgiveness. Participants completed all parts of the current study over the Internet. After giving informed consent, participants completed the disgust sensitivity measure and the voodoo doll task.

\section{Results}

Responses on the voodoo doll task had a highly skewed distribution, with $71 \%$ of participants selecting one pin to insert into the doll representing their partner. To account for the nonnormal distribution of our data, we specified a Poisson distribution in our regression models with robust standard errors.

We predicted that disgust sensitivity would be associated with fewer pins inserted into the doll. As predicted, disgust sensitivity was negatively associated with the number of pins participants chose to put in the doll, $B=-0.02, \chi^{2}(1, N=51)=11.39, p=$ .001 .

We next explored the associations between the three disgust subscales and the number of pins chosen to be inserted into the doll. Moral Disgust was negatively associated with number of pins inserted, $B=-0.04, \chi^{2}(1, N=51)=4.30, p=.04$. Sexual Disgust was also negatively associated with the number of pins inserted, $B=-0.04, \chi^{2}(1, N=51)=4.03, p=.05$. Last, Pathogen Disgust was negatively associated with the number of pins inserted, $B=-0.06, \chi^{2}(1, N=51)=7.38, p=.007$.

\section{Discussion}

The results of Study 3 replicated and extended the effects observed in Studies 1 and 2. Whereas the previous studies showed that disgust sensitivity predicted less trait physical aggression and behavioral aggression against strangers, Study 3 showed that this effect can also be applied to aggressive inclinations towards a romantic partner. Additionally, Studies 1 and 2 showed that the effect of disgust sensitivity on aggressive inclinations was most reliable for the moral and sexual domains and not the pathogen domain of disgust. Yet, in Study 3, the relationship between disgust sensitivity and aggressive inclinations was reliable for the pathogen domain. Because the relationship between pathogen disgust sensitivity was found in only one of the first three studies, this relationship should be interpreted with caution. The findings thus far show consistent evidence for a link between disgust sensitivity and aggression.

Study 4: Trait Disgust Sensitivity Predicts Less Physical Aggression and Approval of Intimate Partner Violence Over Time

The first three studies provided converging support that disgust sensitivity predicts lower aggression. In Study 4, we sought to 
replicate and extend the effects observed between disgust sensitivity and aggression in a longitudinal design, in order to address directionality problems inherent in cross-sectional research. Specifically, we examined whether disgust sensitivity predicted lower trait physical aggression and attitudes towards intimate partner violence over time. We focused on trait physical aggression in Study 4 because it is most strongly related to behavioral aggression (Giancola \& Parrott, 2008). Participants reported their trait disgust sensitivity, physical aggression, and attitudes towards intimate partner violence at Time 1 . After 1 month, participants returned to complete Time 2 measures of each scale. We expected that participants who were high in disgust sensitivity would tend to be less physically aggressive and more disapproving of intimate partner violence in cross-lagged analyses.

\section{Method}

Participants. Participants were 247 undergraduates (78\% women) who reported involvement in an exclusive romantic relationship. Participant relationship length was reported as 2 years or more $(40.7 \%)$, between 19 and 24 months $(8.2 \%)$, between 13 and 18 months (11.5\%), between 7 and 12 months (7.4\%), between 4 and 6 months $(10.3 \%)$, between 2 and 3 months $(14.8 \%)$, and less than 2 months $(7 \%)$. Students earned course credit for their participation in the study.

\section{Measures.}

Disgust sensitivity. As in the previous studies, participants completed the Three Domains of Disgust Scale (Tybur et al., 2009; Time 1 Cronbach's $\alpha=.91$; Time 2 Cronbach's $\alpha=.90$ ).

Trait physical aggression. Participants completed the nineitem Physical Aggression subscale (e.g., "Given enough provocation today, I might hit another person") of the AQ (Buss \& Perry, 1992; Time 1 Cronbach's $\alpha=.88$; Time 2 Cronbach's $\alpha=.86$ ).

Attitudes towards intimate partner violence. To assess attitudes towards intimate partner violence, participants completed the Violence subscale of the Intimate Partner Violence Attitudes Scale-Revised (IPVAS-R; Fincham, Cui, Braithwaite, \& Pasley, 2008). The Violence subscale asks participants to rate their agreement from 1 (strongly disagree) to 5 (strongly agree) on four items measuring disapproval of violence against a romantic partner (e.g., "It would never be appropriate to hit or try to hit one's partner with an object"). The items were summed to create a composite measure, where higher numbers equate to greater disapproval of partner violence (Time 1 Cronbach's $\alpha=.85$; Time 2 Cronbach's $\alpha=$ $.88)$. To improve interpretation of the results, we reverse-scored the scale (i.e., multiplied scores by -1 ), so that larger values indicate greater approval of intimate partner violence.

Procedure. Data for the present study come from a larger project about relationship well-being. Participants arrived to the lab to complete trait-level measures (including the disgust scale, the aggression items, and the IPVAS-R) for their initial visit. Next, participants returned to the lab 4 weeks later for their final visit, where they completed the same trait measures.

\section{Results}

Analysis plan. We predicted that disgust sensitivity would be negatively associated with physical aggression and approval of intimate partner violence over time. Specifically, we examined whether disgust sensitivity at Time 1 predicted a decrease in trait physical aggression and a decrease in approval of intimate partner violence at Time 2, controlling for initial physical aggression and initial attitudes towards intimate partner violence. To properly test this hypothesis, we employed structural equation modeling techniques to examine the cross-lagged effects of disgust sensitivity on physical aggression and approval of intimate partner violence. Our cross-lagged model was evaluated using AMOS 18.0 (Arbuckle, 2009). Because a nonsignificant chi-square is dependent on sample size, several fit indices were used to assess model fit, including the comparative fit index (CFI), the normed fit index (NFI), and the root-mean-square error of approximation (RMSEA; Hoyle, 1995). Because there were missing data among 49 cases between Time 1 and Time 2, full-information maximum likelihood estimation was applied. Bivariate correlations among all variables are presented in Table 1.

Cross-lagged model. We specified a latent variable for Time 1 disgust sensitivity using composite scores from each subscale of Time 1 disgust sensitivity (i.e., Moral, Sexual, and Pathogen Disgust Sensitivity). This latent variable was specified to predict a

Table 1

Bivariate Correlations Among the Three Domains of Disgust Subscales, Trait Physical Aggression, and the IPVAS Violence Subscale at Times 1 and 2: Study 4

\begin{tabular}{|c|c|c|c|c|c|c|c|c|c|c|}
\hline Variable & 1 & 2 & 3 & 4 & 5 & 6 & 7 & 8 & 9 & 10 \\
\hline 1. T1 sexual disgust sensitivity & - & & & & & & & & & \\
\hline 2. T1 moral disgust sensitivity & $.47^{* * * *}$ & - & & & & & & & & \\
\hline 3. T1 pathogen disgust sensitivity & $.58^{* * * *}$ & $.43^{* * *}$ & - & & & & & & & \\
\hline 4. T1 physical aggression & $-.26^{* * *}$ & $-.14^{*}$ & -.10 & - & & & & & & \\
\hline 5. T1 IPV approval & $-.13^{*}$ & $-.24^{* * *}$ & $-.17^{* *}$ & $.16^{*}$ & - & & & & & \\
\hline 6. T2 sexual disgust sensitivity & $.74^{* * * *}$ & $.23^{* * * *}$ & $.31^{* * * *}$ & $-.28^{* * * *}$ & -.07 & - & & & & \\
\hline 7. T2 moral disgust sensitivity & $.47^{* * * *}$ & $.58^{* * *}$ & $.17^{*}$ & $-.15^{*}$ & $-.18^{* *}$ & $.43^{* * * *}$ & - & & & \\
\hline 8. T2 pathogen disgust sensitivity & $.35^{* * *}$ & $.20^{* *}$ & $.64^{* * * *}$ & -.07 & -.07 & $.51^{* * * *}$ & $.43^{* * * *}$ & - & & \\
\hline 9. T2 physical aggression & $-.28^{* * *}$ & $-.21^{* *}$ & -.09 & $.82^{* * * * *}$ & $.23^{* * * *}$ & $-.26^{* * * *}$ & $-.20^{* *}$ & -.06 & - & \\
\hline 10. T2 IPV approval & -.13 & $-.21^{* *}$ & $-.18^{* *}$ & $.14^{*}$ & $.34^{* * * *}$ & -.07 & $-.18^{* *}$ & -.13 & $.15^{*}$ & - \\
\hline$M$ & 32.94 & 35.11 & 36.89 & 22.21 & -17.40 & 32.63 & 33.39 & 35.52 & 20.82 & -17.34 \\
\hline$S D$ & 10.45 & 9.46 & 8.53 & 10.77 & 3.94 & 10.15 & 9.49 & 8.47 & 10.28 & 4.18 \\
\hline
\end{tabular}

Note. $\quad$ IPVAS $=$ Intimate Partner Violence Attitudes Scale; $\mathrm{T} 1=$ Time $1 ; \mathrm{T} 2=$ Time 2; IPV $=$ intimate partner violence.

${ }^{*} p<.05 .{ }^{* *} p<.01 .{ }^{* * *} p<.001$. 
latent variable for Time 2 disgust sensitivity, as well as composite scores of Time 2 physical aggression and Time 2 approval of intimate partner violence. We then modeled the direct effects of Time 1 physical aggression and Time 1 approval of intimate partner violence onto their corresponding Time 2 measures, as well as the latent variable for Time 2 disgust sensitivity. All Time 1 variables were permitted to covary, as well as each of the Time 2 variables. Error terms on each of the indicators of Time 1 disgust sensitivity were permitted to covary with the error term of its corresponding Time 2 indicator.

The fit indices for the resulting cross-lagged model (see Figure 1) indicated good fit, $\chi^{2}(23, N=247)=41.84, p=.009, \chi^{2} / d f=$ $1.82, C F I=.98, N F I=.96, R M S E A=.058(90 \% \mathrm{CI}=[.028$, $.085]$ ). As predicted, the cross-lagged effect of disgust sensitivity at Time 1 on physical aggression at Time 2 was significant $(\beta=$ $-.09, p=.05)$. Participants who were more sensitive to disgust at Time 1 reported being less physically aggressive at Time 2, controlling for initial levels of trait physical aggression. Similarly, the cross-lagged effect of disgust sensitivity at Time 1 on approval of intimate partner violence at Time 2 was significant $(\beta=-.18, p=$ $.02)$. Participants who were more sensitive to disgust at Time 1 expressed less approval of intimate partner violence at Time 2, controlling for initial approval of intimate partner violence. Neither the cross-lagged effect of physical aggression at Time 1 on disgust sensitivity at Time 2 nor the cross-lagged effect of approval of intimate partner violence at Time 1 on disgust sensitivity at Time 2 was significant $(\beta=-.12, p=.09$ and $\beta=-.02, p=$ .80 , respectively). ${ }^{1}$

\section{Discussion}

Study 4 replicated and extended the findings observed in Studies 1-3. Disgust sensitivity predicted less physical aggression and less approval of intimate partner violence longitudinally. Our data speak to the directionality of these relationships, as the crosslagged effects between Time 1 disgust sensitivity and Time 2 physical aggression and Time 2 approval of intimate partner violence were significant, whereas the reversed cross-lagged effects were not. That is, disgust sensitivity was a significant predictor of aggressive tendencies over time, but aggressive tendencies were not significant predictors of disgust sensitivity over time, providing evidence for the direction of the effects. Together, these findings support the hypothesis that sensitivity to disgust is a buffering factor with aggression.

\section{Study 5: Daily Sensitivity to Disgust Predicts Less Daily Aggression}

Studies 1-4 provided converging support that disgust sensitivity predicts lower aggression, both cross-sectionally and longitudinally. In Study 5, we sought to replicate and extend the effects observed between disgust sensitivity and aggression at the daily level. Specifically, we sought to provide a more powerful test by exploring the different contexts that should provoke the influence of disgust sensitivity on aggression in everyday life.

Disgust sensitivity is composed of three distinct functional domains (i.e., moral, sexual, and pathogen disgust; Tybur et al., 2009). Therefore, we explored whether each domain of disgust would have a differential effect on daily aggression when various feelings and situations related to each domain arise. We again focused on the Physical Aggression subscale of the AQ (Buss \& Perry, 1992) in Study 5 because it is most strongly related to behavioral aggression (Giancola \& Parrott, 2008). For three times a week over a 25-day period (total of 10 waves), participants reported on daily feelings related to each domain of disgust, as well as completed daily measures of disgust sensitivity and aggression. We predicted that daily sensitivity to moral disgust, sexual disgust, and pathogen disgust would buffer people from aggression in situations that provoke moral disgust, sexual disgust, and pathogen disgust, respectively.

\section{Method}

Participants. Participants were 166 undergraduate students (76\% women) who participated for partial course credit.

Measures.

Daily disgust sensitivity. Participants completed an abbreviated form of the Three Domains of Disgust Scale, which was modified for daily use to include the three items with the highest factor loadings from each domain reported in Tybur et al. (2009). Participants completed three items measuring daily sensitivity to pathogen disgust (e.g., "Standing close to a person who has body odor"; Cronbach's $\alpha=.81$ ), sexual disgust (e.g., "Watching a pornographic video"; Cronbach's $\alpha=.77$ ), and moral disgust (e.g., "Stealing from a neighbor"; Cronbach's $\alpha=.88$ ). Subscale items were summed to form composites of daily pathogen, sexual, and moral disgust sensitivity, with greater numbers indicating greater disgust sensitivity.

Daily intensity of feeling morally offended. To assess how much participants experienced a situation that may evoke moral disgust, participants completed a one-item measure that assessed how morally offended they felt that day on a 7-point scale (from not at all to extremely; $M=1.53, S D=1.12$ ).

Daily frequency of sexual fantasy. To assess how much participants experienced a situation that may evoke sexual disgust, participants completed a one-item measure that assessed how many sexual fantasies they have had since their last $\log (M=1.78$, $S D=1.58)$.

Daily impulse to vomit. To assess how much participants experienced a situation that may evoke pathogen disgust, participants completed a one-item measure that assessed how much they had experienced the impulse to vomit after eating that day on a 6-point scale (from not at all to all the time; $M=1.16, S D=$ $0.69)$.

Daily physical aggression. Participants completed an abbreviated form of the Physical Aggression subscale of the AQ (Buss \& Perry, 1992), which was modified for daily use. Participants completed two items measuring physical aggression (i.e., "Given enough provocation today, I might hit another person," and "If I

\footnotetext{
${ }^{1}$ We specified an alternate model in which each domain of the disgust sensitivity scale independently predicted trait physical aggression and approval of intimate partner violence over time. However, this model resulted in poorer fit with an Akaike information criterion (AIC) of 135.15 and a root-mean-square error of approximation (RMSEA) of .08, compared with the AIC of 125.84 and the RMSEA of .05 from the model reported in Study 4. Given prior recommendations for fit indicators (Hoyle, 1995), the model reported in Study 4 was the best fitting model.
} 


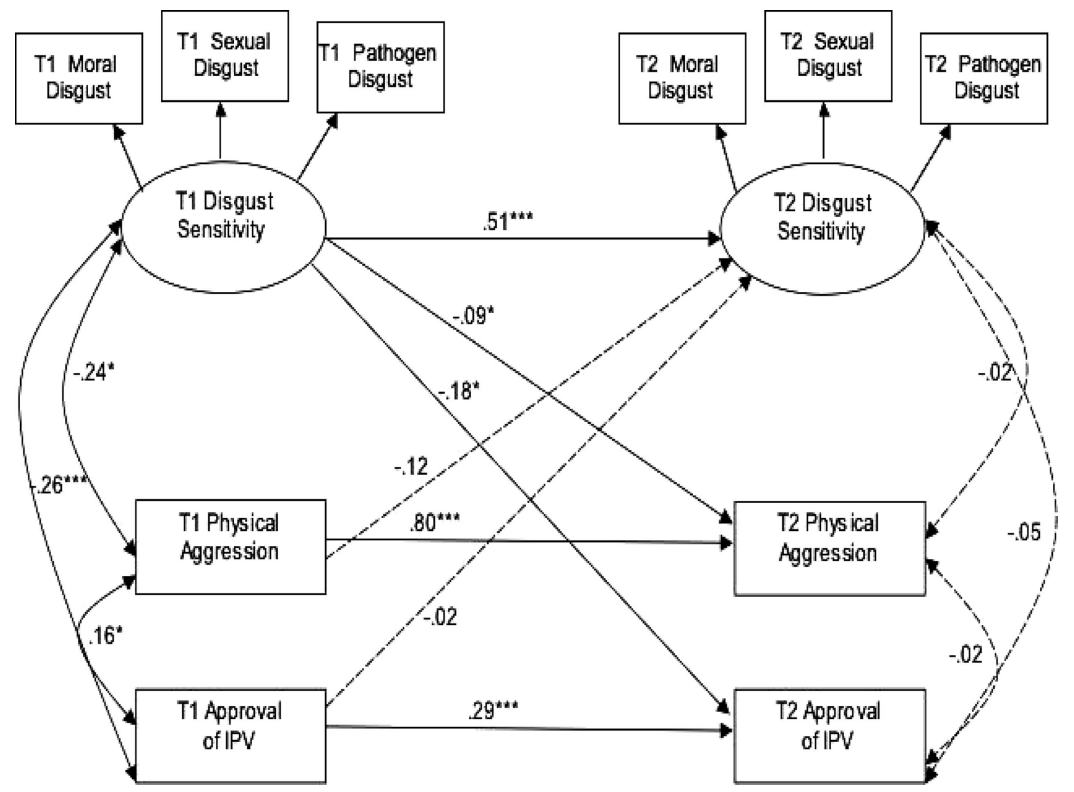

Figure 1. Cross-lagged model with disgust sensitivity, physical aggression, and attitudes towards intimate partner violence measured at two time points: Study 4. Standardized coefficients are reported, and dashed lines indicate nonsignificant paths. T1 $=$ Time $1 ; \mathrm{T} 2=$ Time $2 ; \mathrm{IPV}=$ intimate partner violence. ${ }^{*} p<.05 .{ }^{* * * *} p<$ .001 .

had to resort to violence to protect my rights, I would today"; Cronbach's $\alpha=.80$ ). Responses across the items were summed to form a composite measure of daily physical aggression, with higher numbers indicating greater aggression.

Procedure. Participants were given a URL at which to record their feelings and behaviors three times each week for 25 days, which included the measures of disgust sensitivity, feelings of being morally offended, frequency of sexual fantasies, impulse to vomit, and physical aggression. Participants were instructed to complete their daily surveys at the end of each day before midnight. To increase compliance, researchers stressed that receiving full participation credit was contingent on timely reporting and that a time-date stamp would be recorded on each log. All information submitted via online survey was confidential and stored on a secure server. A debriefing followed.

\section{Results}

Analysis plan. Our main prediction was that sensitivity to each domain of disgust (i.e., moral, sexual, and pathogen disgust) would provide the strongest buffer to aggression in contexts specific to those domains. That is, feeling morally offended on a given day should relate to less aggression among participants who are more sensitive to moral disgust, compared with participants who are less sensitive to moral disgust. Similarly, having sexual fantasies on a given day should relate to less aggression among participants who are more sensitive to sexual disgust, compared with participants who are less sensitive to sexual disgust. Last, feeling the impulse to vomit on a given day should relate to less aggression among participants who are more sensitive to pathogen disgust, compared with participants who are less sensitive to pathogen disgust. Because the data violate the assumption of independence in ordinary least squares regression (i.e., daily measures nested within individual participants), we used multilevel modeling techniques to account for their nested structure, using HLM Version 6.08 (Nezlek, 2001; Raudenbush \& Bryk, 2002; Raudenbush, Bryk, Cheong, \& Congdon, 2000). A total of 1,330 days of data were provided by 166 participants $(M=8.01)$. We assessed the reliability of our daily measures using a three-level modeling procedure with items nested within days and days nested within people (see Nezlek, 2007, for rationale). We found that our items for daily moral disgust sensitivity, daily sexual disgust sensitivity, daily pathogen disgust sensitivity, daily feelings of moral offense, daily sexual fantasies, daily impulse to vomit, and daily aggression were reliable (estimates ranged between .76 and .97).

Does daily sensitivity to moral disgust moderate the effect of feeling morally offended on daily physical aggression? To address whether the moral domain of disgust sensitivity interacted with feeling offended to predict less aggression, we modeled daily aggression as a function of daily feelings of moral offense and its interaction with each domain of disgust sensitivity, using Equation 1:

Physical aggression $=\beta_{0 j}+\beta_{1 j}$ (felt offended)

$+\beta_{2 j}$ (moral disgust sensitivity)

$+\beta_{3 j}$ (sexual disgust sensitivity)

$+\beta_{4 j}$ (pathogen disgust sensitivity)

$+\beta_{5 j}$ (Moral Disgust Sensitivity $\times$ Felt Offended $)$

$+\beta_{6 j}($ Sexual Disgust Sensitivity $\times$ Felt Offended $)$

$+\beta_{7 j}$ (Pathogen Disgust Sensitivity $\times$ Felt Offended $)+r_{i j}$, 
where $\beta_{0 j}$ represents the initial physical aggression of person $j$; $\beta_{1 j}$ estimates the within-person association between daily feelings of moral offense and physical aggression, controlling for the associations between physical aggression and each of the other variables in Equation $1 ; \beta_{2 j}$ estimates the within-person association between daily sensitivity to moral disgust and physical aggression, controlling for the associations between physical aggression and each of the other variables in Equation 1; $\beta_{3 j}$ estimates the within-person association between daily sensitivity to sexual disgust and physical aggression, controlling for the associations between physical aggression and each of the other variables in Equation $1 ; \beta_{4 j}$ estimates the within-person association between daily sensitivity to pathogen disgust and physical aggression, controlling for the associations between physical aggression and each of the other variables in Equation $1 ; \beta_{5 j}$ estimates the interaction between moral disgust sensitivity and feelings of moral offense on physical aggression, controlling for the associations between physical aggression and each of the other variables in Equation $1 ; \beta_{6 j}$ estimates the interaction between sexual disgust sensitivity and feelings of moral offense on physical aggression, controlling for the associations between physical aggression and each of the other variables in Equation $1 ; \beta_{7 j}$ estimates the interaction between pathogen disgust sensitivity and feelings of moral offense on physical aggression, controlling for the associations between physical aggression and each of the other variables in Equation 1 ; and $r_{i j}$ is the residual variance in repeated measurements for person $j$, assumed to be independent and normally distributed across individuals.

As expected, analyses revealed a significant Moral Disgust Sensitivity $\times$ Feeling Offended interaction, $B=-0.30$, $t(1297)=-2.85, p=.005$. Neither daily sensitivity to sexual disgust nor pathogen disgust interacted with feeling morally offended to predict aggression, $B=0.11, t(1297)=0.80, p=$ .43 , and $B=-0.02, t(1297)=-0.24, p=.81$, respectively. Additionally, there was a main effect for daily feelings of moral offense, such that, on average, people report more aggression on days when they feel morally offended, $B=0.28, t(1297)=$ $3.24, p=.002$. There were no significant main effects for daily sensitivity to moral disgust, $B=-0.05, t(1297)=-1.13$, $p=.26$; daily sensitivity to sexual disgust, $B=-0.07$, $t(1297)=-1.44, p=.15$; or daily sensitivity to pathogen disgust, $B=0.02, t(1297)=0.53, p=.60$.

To evaluate the nature of our interaction effect, we examined the association between daily feelings of being offended and daily physical aggression among participants relatively low $(-1 S D)$ and high $(+1 S D)$ in moral disgust sensitivity (Aiken \& West, 1991). Among participants low in moral disgust sensitivity, feeling morally offended predicted increased daily aggression $(B=1.75, t=$ $3.36, p=.0008)$. Among participants high in moral disgust sensitivity, feeling morally offended predicted decreased daily aggression $(B=-1.19, t=-2.27, p=.02)$.

Does daily sensitivity to sexual disgust moderate the effect of sexual fantasies on daily physical aggression? To address whether the sexual domain of disgust sensitivity interacted with frequency of sexual fantasies to predict less aggression, we modeled daily aggression as a function of daily sexual fantasies and its interaction with each domain of disgust sensitivity, using Equation 2:
Physical aggression $=\beta_{0 j}+\beta_{1 j}($ sexual fantasies $)$

$+\beta_{2 j}$ (moral disgust sensitivity)

$+\beta_{3 j}$ (sexual disgust sensitivity)

$+\beta_{4 j}$ (pathogen disgust sensitivity)

$+\beta_{5 j}$ (Moral Disgust Sensitivity $\times$ Sexual Fantasies $)$

$+\beta_{6 j}($ Sexual Disgust Sensitivity $\times$ Sexual Fantasies $)$

$+\beta_{7 j}$ (Pathogen Disgust Sensitivity $\times$ Sexual Fantasies $)+r_{i j}$,

where $\beta_{0 j}$ represents the initial physical aggression of person $j ; \beta_{1 j}$ estimates the within-person association between daily frequency of sexual fantasies and physical aggression, controlling for the associations between physical aggression and each of the other variables in Equation 2; $\beta_{2 j}$ estimates the within-person association between daily sensitivity to moral disgust and physical aggression, controlling for the associations between physical aggression and each of the other variables in Equation 2; $\beta_{3 j}$ estimates the withinperson association between daily sensitivity to sexual disgust and physical aggression, controlling for the associations between physical aggression and each of the other variables in Equation $2 ; \beta_{4 j}$ estimates the within-person association between daily sensitivity to pathogen disgust and physical aggression, controlling for the associations between physical aggression and each of the other variables in Equation 2; $\beta_{5 j}$ estimates the interaction between moral disgust sensitivity and sexual fantasies on physical aggression, controlling for the associations between physical aggression and each of the other variables in Equation $2 ; \beta_{6 j}$ estimates the interaction between sexual disgust sensitivity and sexual fantasies on physical aggression, controlling for the associations between physical aggression and each of the other variables in Equation 2; $\beta_{7 j}$ estimates the interaction between pathogen disgust sensitivity and sexual fantasies on physical aggression, controlling for the associations between physical aggression and each of the other variables in Equation 2; and $r_{i j}$ is the residual variance in repeated measurements for person $j$, assumed to be independent and normally distributed across individuals.

As expected, analyses revealed a significant Sexual Disgust Sensitivity $\times$ Sexual Fantasies interaction, $B=-0.16, t(1301)=$ $-2.06, p=.04$. Neither daily sensitivity to moral disgust nor pathogen disgust interacted with sexual fantasies to predict aggression, $B=-0.05, t(1301)=-0.55, p=.58$, and $B=-0.06$, $t(1301)=-0.86, p=.39$, respectively. There were no significant main effects for daily sexual fantasies, $B=-0.003, t(1301)=$ $-0.05, p=.96$; daily sensitivity to moral disgust, $B=-0.05$, $t(1301)=-1.20, p=.23$; daily sensitivity to sexual disgust, $B=$ $-0.04, t(1301)=-0.89, p=.37$; or daily sensitivity to pathogen disgust, $B=-0.004, t(1301)=-0.10, p=.93$.

To evaluate the nature of our interaction effect, we examined the association between daily sexual fantasies and daily physical aggression among participants relatively low (-1 SD) and high (+1 $S D$ ) in sexual disgust sensitivity (Aiken \& West, 1991). Among participants low in sexual disgust sensitivity, having sexual fantasies was related to increased daily aggression $(B=0.76, t=2.19$, $p=.03$ ). Among participants high in sexual disgust sensitivity, 
having sexual fantasies was related to decreased daily aggression $(B=-0.76, t=-1.89, p=.059)$.

Does daily sensitivity to pathogen disgust moderate the effect of impulse to vomit on daily physical aggression? To address whether the pathogen domain of disgust sensitivity interacted with daily impulse to vomit to predict less aggression, we modeled daily aggression as a function of daily impulse to vomit and its interaction with each domain of disgust sensitivity, using Equation 3:

Physical aggression $=\beta_{0 j}+\beta_{1 j}$ (impulse to vomit)

$+\beta_{2 j}$ (moral disgust sensitivity)

$+\beta_{3 j}$ (sexual disgust sensitivity)

$+\beta_{4 j}$ (pathogen disgust sensitivity)

$+\beta_{5 j}$ (Moral Disgust Sensitivity $\times$ Impulse to Vomit $)$

$+\beta_{6 j}$ (Sexual Disgust Sensitivity $\times$ Impulse to Vomit $)$

$+\beta_{7 j}$ (Pathogen Disgust Sensitivity $\times$ Impulse to Vomit $)+r_{i j}$,

where $\beta_{0 j}$ represents the initial physical aggression of person $j ; \beta_{1 j}$ estimates the within-person association between daily impulse to vomit and physical aggression, controlling for the associations between physical aggression and each of the other variables in Equation 3; $\beta_{2 j}$ estimates the within-person association between daily sensitivity to moral disgust and physical aggression, controlling for the associations between physical aggression and each of the other variables in Equation 3; $\beta_{3 j}$ estimates the within-person association between daily sensitivity to sexual disgust and physical aggression, controlling for the associations between physical aggression and each of the other variables in Equation $3 ; \beta_{4 j}$ estimates the within-person association between daily sensitivity to pathogen disgust and physical aggression, controlling for the associations between physical aggression and each of the other variables in Equation 3; $\beta_{5 j}$ estimates the interaction between moral disgust sensitivity and daily impulse to vomit on physical aggression, controlling for the associations between physical aggression and each of the other variables in Equation $3 ; \beta_{6 j}$ estimates the interaction between sexual disgust sensitivity and impulse to vomit on physical aggression, controlling for the associations between physical aggression and each of the other variables in Equation 3; $\beta_{7 j}$ estimates the interaction between pathogen disgust sensitivity and impulse to vomit on physical aggression, controlling for the associations between physical aggression and each of the other variables in Equation 3; and $r_{i j}$ is the residual variance in repeated measurements for person $j$, assumed to be independent and normally distributed across individuals.

As expected, analyses revealed a significant Pathogen Disgust Sensitivity $\times$ Impulse to Vomit interaction, $B=-0.21, t(1295)=$ $-2.92, p=.004$. Neither daily sensitivity to moral disgust nor sexual disgust interacted with impulse to vomit to predict aggression, $B=0.17, t(1295)=1.66, p=.10$, and $B=-0.06, t(1295)=$ $-0.55, p=.58$, respectively. There were no significant main effects for daily impulse to vomit, $B=0.03, t(1295)=0.20, p=$ .85 ; daily sensitivity to moral disgust, $B=-0.05, t(1295)=-1.14$, $p=.25$; daily sensitivity to sexual disgust, $B=-0.06, t(1295)=$
$-1.28, p=.20$; or daily sensitivity to pathogen disgust, $B=0.01$, $t(1295)=0.22, p=.83$.

To evaluate the nature of our interaction effect, we examined the association between daily impulse to vomit and daily physical aggression among participants relatively low ( $-1 S D)$ and high $(+1 S D)$ in pathogen disgust sensitivity (Aiken \& West, 1991). Among participants low in pathogen disgust sensitivity, daily impulse to vomit predicted increased daily aggression $(B=0.86$, $t=2.53, p=.01)$. Among participants high in pathogen disgust sensitivity, a daily impulse to vomit was related to less daily aggression $(B=-0.80, t=-2.74, p=.006)$.

\section{Discussion}

Study 5 extends the previous studies by showing that each functional domain of disgust sensitivity may serve as a buffer against aggression, depending on the daily context. That is, people high in moral disgust sensitivity are buffered from aggression when they experience feelings and situations that activate the moral domain. People high in sexual disgust sensitivity are buffered from aggression when they experience feelings and situations that activate the sexual domain. Last, people high in pathogen disgust sensitivity are buffered from aggression when they experience feelings and situations that activate the pathogen domain.

\section{General Discussion}

Violence pervades human culture, often with severe personal and societal consequences. Prior work has focused on the negative states or events that precede aggression (e.g., Anderson et al., 1995; Bushman \& Baumeister, 1998; Bushman et al., 2005; DeWall \& Bushman, 2009; Twenge et al., 2001), particularly the emotional state of anger (Berkowitz, 1983, 1990). Yet more recent studies highlight the importance of considering not just the valence of an emotion but also its motivational direction (e.g., HarmonJones et al., 2009; Wilkowski \& Meier, 2010). Both anger and behavioral aggression are linked to trait approach motivation (Harmon-Jones, 2003). With this in mind, we sought to explore the association between sensitivity to a negatively valenced, avoidance-motivated emotional state and aggression.

Specifically, we hypothesized that disgust sensitivity would predict less aggression. Disgust is one component of the behavioral immune system, which promotes behavioral avoidance as a way of protecting oneself from microbial contamination and social transgressors (Schaller \& Duncan, 2007). Primed feelings of disgust, as well as dispositional disgust sensitivity, are associated with behavioral avoidance and withdrawal (Olatunji et al., 2008). Because aggression is approach oriented and disgust is linked with behavioral avoidance, those who feel the most disgusted should behave the least aggressively.

The results of five studies provided converging evidence that disgust sensitivity is negatively associated with aggression. Using one of the most widely used indicators of trait aggression (Buss \& Perry, 1992), Study 1 showed that disgust sensitivity predicted less physical and verbal aggression. Study 2 replicated and extended this effect using a laboratory measure of behavioral aggression. Study 3 demonstrated that these effects generalized to aggressive inclinations towards a romantic relationship partner. In Study 4 , we examined the directionality of the association between disgust 
sensitivity and aggression by replicating the effects observed in Studies 1-3 longitudinally. We found that disgust sensitivity predicted decreased trait physical aggression and decreased approval of intimate partner violence over a 4-week period, controlling for initial physical aggression and attitudes towards intimate partner violence. Finally, a daily diary study demonstrated that each domain of disgust sensitivity had a unique effect in buffering aggression when specific feelings and events activated those domains.

Disgust is a defensive emotion that orients people towards avoidant-type behaviors, which is in direct conflict with the approach-related motivational direction of aggression (HarmonJones, 2003). As such, we expected a consistent relationship between a general sensitivity to disgust and aggression. Yet, the general effect of disgust sensitivity on aggression may be an artifact driven by one specific domain of disgust sensitivity (i.e., moral, sexual, or pathogen disgust). For example, the domain of moral disgust might be a stronger predictor of aggressive behavior, as people who are sensitive to moral offenses might be less likely to want to hurt others. On the other hand, violence often results in open wounds of one's victims. Perhaps people who are more disgusted by pathogens, or have a higher perceived vulnerability to disease, are less likely to aggress against others to avoid contamination by open wounds. Studies 1-4 focused on participants' overall sensitivity to disgust because of the strong theoretical background linking disgust to behavioral avoidance (Schaller \& Duncan, 2007).

Nonetheless, we explored whether each domain correlated with less aggression and found that both moral and sexual disgust sensitivity were consistently associated with less aggression, whereas pathogen disgust sensitivity related to less aggression inconsistently. One explanation for this pattern is that specific disgust cues were not readily salient, as the focus of Studies 1-4 concerned people's general tendency to aggress against others. If contextual cues related to each domain were apparent, then perhaps each domain of disgust sensitivity would have a stronger influence on reducing aggressive tendencies. Consistent with this hypothesis, Study 5 demonstrated that people high in moral disgust sensitivity are buffered from aggression in situations when moral disgust is especially relevant (i.e., feeling morally offended). Likewise, people high in sexual disgust sensitivity are less aggressive in situations when sexual disgust is relevant (i.e., having sexual fantasies). Finally, people high in pathogen disgust sensitivity are buffered from aggression in situations when pathogen disgust is especially relevant (i.e., having the impulse to vomit). These moderating effects provide the strongest test of our hypothesis that high disgust sensitivity should predict less aggression. As well, this work is an example of how disgust sensitivity may interact with specific events in people's daily lives to influence their behavior.

\section{Disgust, Ostracism, and Anger}

In the current investigation, we argue that disgust sensitivity is related to less aggression because it orients people towards behavioral avoidance, which is in conflict with the motivational direction of aggression. Yet, at face value, these findings may seem peculiar. Disgust sensitivity and contamination fears are linked to negative attitudes towards out-group members (Faulkner et al., 2004; Inbar et al., 2009; Navarrete \& Fessler, 2006; Park et al., 2003). One might expect that having a lower tolerance for social transgressors or out-group members would lead to more aggressive behavior towards those individuals. One possibility is that, instead of actively aggressing against others, disgusted individuals do harm by ostracizing stigmatized individuals. Indeed, previous work demonstrates that disgust-sensitive individuals have the desire to exclude out-group members (Faulkner et al., 2004; Navarrete \& Fessler, 2006). Another possibility may be that avoidant emotions, such as disgust and fear, provoke anger and aggression when the actor is unable to get out of the threatening situation.

A second issue concerns how people often conflate the emotions of disgust and anger. When people say that they are disgusted, they sometimes mean that they really are angry. Even daily self-reports of feeling disgusted can demonstrate high loadings on anger (Diener, Smith, \& Fujita, 1995). In such cases, we would expect feeling disgusted to correlate with increased aggression, as anger and aggression share the same motivational direction (Carver, 2004; Harmon-Jones, 2003). Yet, in Study 1 of the current investigation, disgust sensitivity related to less physical and verbal aggression, while demonstrating no relation to trait anger. Additionally, although people often conflate disgust and anger in everyday speech, disgust and anger are independent emotional categories with unique facial cues and distinctive physiological responses (Ekman \& Friesen, 1975; Levenson, 1992). Distinctly different types of threat also elicit disgust and anger. For instance, groups that elicit disgust represent a contamination risk to one's in-group (e.g., threat to health, threat to group values), whereas groups that provoke anger are those that pose obstacles to one's goals (e.g., threat to property, threat to personal freedom; Cottrell \& Neuberg, 2005).

Our results demonstrate the utility of considering the motivational direction of emotional states when predicting aggression. This work can inform future research and theory on aggressive behavior, particularly within the perspective of the general aggression model (GAM; Anderson \& Bushman, 2002; DeWall \& Anderson, 2011). Our results are consistent with the GAM because the knowledge structures associated with disgust promote behavioral avoidance, and behavioral avoidance should be associated with lower levels of aggression. Similarly, other emotional states that are linked to avoidance motivation (e.g., anxiety, fear) may also predict less aggression in certain circumstances. Disgust facilitates avoidant behaviors that potentially protect us from infection and contamination (Mortensen et al., 2010; Olatunji et al., 2008). Our results show that this emotion also serves an additional protective function by motivating us to avoid potentially harmful physical conflict. More broadly, the current work adds to the corpus of research that highlights the role of emotions in predicting aggression. By understanding how emotions can influence aggressive behavior, over and above the effect of their valence, scientists can gain a clearer understanding of the factors that increase and decrease violence.

\section{Limitations and Future Directions}

The current investigation provided consistent support for the hypothesis that disgust sensitivity is negatively associated with violence over a variety of different methods. Despite the consistency of our findings, several limitations may prove beneficial in generating future research ideas. The first limitation is that our 
studies relied on the use of U.S. samples, leaving the question of cross-cultural universality open. The current effects may differ within other cultures. The socialization processes of other cultures may present different behavioral scripts in response to distinct disgust elicitors. Although disgust may be elicited through different stimuli across cultures, the emotion itself is culturally universal (Ekman \& Friesen, 1975). Therefore, we would expect our effects to replicate in other cultures given the fundamental nature of disgust, but the situational factors that give rise to disgust may differ across cultures.

If the cross-cultural behavioral response to disgust is avoidance, would disgust still decrease aggression among people who live in non-warring societies? Recent anthropological evidence highlights the fact that many egalitarian, hunter-gatherer societies exist where warfare is essentially nonexistent (Fry, 2007). Yet, even within these non-warring cultures, the potential for physical aggression is still present. Physical conflict does occur in these societies, and therefore disgust sensitivity may play a role in keeping aggressive impulses in check in these largely peaceful cultures.

Another limitation concerns a possible boundary condition for our effects. Our studies suggest that high disgust sensitivity is related to lower levels of aggression. Along with the other benefits of having a disgust response (Schaller \& Duncan, 2007), avoiding physical conflict would appear to have an added advantage. Yet our samples came from a nonclinical undergraduate population. Our results may not generalize to people who have an extreme sensitivity to disgust. Extremely high sensitivity to disgust is linked to various anxiety disorders, particularly contaminationrelated obsessive-compulsive disorder (OCD; Connolly, O'Neill, Flessner, \& Olatunji, 2006; Olatunji, Lohr, Willems, \& Sawchuk, 2006; Olatunji, Sawchuk, Lohr, \& de Jong, 2004). Such patients may experience very low levels of aggressive behaviors, but people who have a clinically severe preoccupation with illness are also likely to be unable to function within their social environments productively. In this case, an overactive behavioral immune system may hamper one's well-being.

The current article proposed that disgust sensitivity would predict less aggression because disgust elicits avoidant motivations and behaviors, which are inconsistent with the behavioral script for aggression. Future work can expand on the present topic by illuminating the neurobiological mechanism that underlies the effect of disgust sensitivity on aggression. Recent work has shown that anger and approach motivation are related to increased left (vs. right) prefrontal cortical activation (Carver \& Harmon-Jones, 2009; Harmon-Jones \& Peterson, 2009), whereas disgust and withdrawal are both associated with right (vs. left) prefrontal and anterior activation (Davidson, 1992; Davidson, Ekman, Saron, Senulis, \& Friesen, 1990). Therefore, individuals with greater sensitivity to disgust may have greater chronic right-lateralized activation that is incongruent with physical aggression.

A final direction may investigate cyclic changes in disgust sensitivity. Specifically, pregnancy sickness among otherwise healthy women is an adaptation that influences women's eating behavior in a way that protects a fetus during an especially vulnerable time of development (Profet, 1992). Symptoms of pregnancy sickness include food aversions, nausea, and vomiting. Women at early stages of pregnancy may also experience a general increase in disgust sensitivity. If a woman's general disposition towards disgust can change across the course of her pregnancy, then this enhanced disgust sensitivity will influence her likelihood of entering a physical conflict. By influencing pregnant mothers to avoid physical conflict, this increased disgust sensitivity may be adding an additional protection for unborn fetuses, namely, protection from physical injury.

\section{Conclusion}

Previous research has focused on the valence of emotional states that cause aggression. The present work supports the proposal that fruitful hypotheses about aggression can be generated by accounting for the motivational direction of these emotional states (Carver \& Harmon-Jones, 2009). Our findings also highlight the importance of considering emotional states that reduce aggression, as opposed to the emotions that increase it.

Humans live in a sometimes brutal and hostile world. And though violence overall may be on the decline (Bushman \& Huesmann, 2010), the ability to cause large-scale devastation is increasing. Such a threat to our personal safety and survival emphasizes the need to investigate the various cognitive, emotional, and situational factors that work to reduce behavioral aggression.

\section{References}

Aiken, L. S., \& West, S. G. (1991). Multiple regression: Testing and interpreting interactions. Thousand Oaks, CA: Sage.

Anderson, C. A., \& Bushman, B. J. (1997). External validity of "trivial" experiments: The case of laboratory aggression. Review of General Psychology, 1, 19-41. doi:10.1037/1089-2680.1.1.19

Anderson, C. A., \& Bushman, B. J. (2002). Human aggression. Annual Review of Psychology, 53, 27-51. doi:10.1146/annurev.psych.53.100901.135231

Anderson, C. A., Deuser, W. E., \& DeNeve, K. (1995). Hot temperatures, hostile affect, hostile cognition, and arousal: Tests of a general model of affective aggression. Personality and Social Psychology Bulletin, 21, 434-448. doi:10.1177/0146167295215002

Arbuckle, J. L. (2009). Amos (Version 18.0) [Computer software]. Chicago, IL: SPSS.

Baron, R. A., \& Richardson, D. R. (1994). Human aggression (2nd ed.). New York, NY: Plenum Press.

Baumeister, R. F., \& Leary, M. R. (1995). The need to belong: Desire for interpersonal attachments as a fundamental human motivation. Psychological Bulletin, 117, 497-529. doi:10.1037/0033-2909.117.3.497

Baumeister, R. F., Smart, L., \& Boden, J. M. (1996). Relation of threatened egotism to violence and aggression: The dark side of high self-esteem. Psychological Review, 103, 5-33. doi:10.1037/0033-295X.103.1.5

Berkowitz, L. (1983). Aversively stimulated aggression: Some parallels and differences in research with animals and humans. American Psy chologist, 38, 1135-1144. doi:10.1037/0003-066X.38.11.1135

Berkowitz, L. (1990). On the formation and regulation of anger and aggression: A cognitive-neoassociationistic analysis. American Psychologist, 45, 494-503. doi:10.1037/0003-066X.45.4.494

Blanchard, D. C., \& Blanchard, R. J. (1984). Affect and aggression: An animal model applied to human behavior. In R. J. Blanchard \& D. C. Blanchard (Eds.), Advances in the study of aggression (Vol. I, pp. 1-62). New York, NY: Academic Press.

Blanchard, D. C., \& Blanchard, R. J. (2003). What can animal aggression research tell us about human aggression? Hormones and Behavior, 44, 171-177. doi:10.1016/S0018-506X(03)00133-8

Brown, J. K. M. (2003). A cost of disease resistance: Paradigm or peculiarity? Trends in Genetics, 19, 667-671. doi:10.1016/j.tig.2003.10.008 
Buckley, K. E., Winkel, R. E., \& Leary, M. R. (2004). Reactions to acceptance and rejection: Effects of level and sequence of relational evaluation. Journal of Experimental Social Psychology, 40, 14-28. doi:10.1016/S0022-1031(03)00064-7

Bushman, B. J., \& Baumeister, R. F. (1998). Threatened egotism, narcissism, self-esteem, and direct and displaced aggression: Does self-love or self-hate lead to violence? Journal of Personality and Social Psychology, 75, 219-229. doi:10.1037/0022-3514.75.1.219

Bushman, B. J., Baumeister, R. F., \& Phillips, C. M. (2001). Do people aggress to improve their mood? Catharsis beliefs, affect regulation opportunity, and aggressive responding. Journal of Personality and Social Psychology, 81, 17-32. doi:10.1037/0022-3514.81.1.17

Bushman, B. J., Baumeister, R. F., \& Stack, A. D. (1999). Catharsis, aggression, and persuasive influence: Self-fulfilling or self-defeating prophecies? Journal of Personality and Social Psychology, 76, 367-376. doi:10.1037/0022-3514.76.3.367

Bushman, B. J., \& Huesmann, L. R. (2010). Aggression. In S. T. Fiske, D. T. Gilbert, \& G. Lindzey (Eds.), Handbook of social psychology (5th ed., pp. 833-863). New York, NY: Wiley.

Bushman, B. J., Ridge, R. D., Das, E., Key, C. W., \& Busath, G. L. (2007). When God sanctions killing: Effect of scriptural violence on aggression. Psychological Science, 18, 204-207. doi:10.1111/j.14679280.2007.01873.x

Bushman, B. J., Wang, M. C., \& Anderson, C. A. (2005). Is the curve relating temperature to aggression linear or curvilinear? Assaults and temperature in Minneapolis reexamined. Journal of Personality and Social Psychology, 89, 62-66. doi:10.1037/0022-3514.89.1.62

Buss, A. H., \& Perry, M. P. (1992). The Aggression Questionnaire. Journal of Personality and Social Psychology, 63, 452-459. doi:10.1037/00223514.63.3.452

Carver, C. S. (2004). Negative affects deriving from the behavioral approach system. Emotion, 4, 3-22. doi:10.1037/1528-3542.4.1.3

Carver, C. S., \& Harmon-Jones, E. (2009). Anger is an approach-related affect: Evidence and implications. Psychological Bulletin, 135, 183204. doi:10.1037/a0013965

Chapman, H. A., Kim, D. A., Susskind, J. M., \& Anderson, A. K. (2009, February 27). In bad taste: Evidence for the oral origins of moral disgust. Science, 323, 1222-1226. doi:10.1126/science.1165565

Connolly, K. M., O’Neill, H. K., Flessner, C. A., \& Olatunji, B. O. (2006). Fear, disgust, and fainting in blood-injection-injury fears: A multimethod approach. Anxiety, Stress \& Coping, 19, 409-420. doi:10.1080/ 10615800601055956

Cottrell, C. A., \& Neuberg, S. L. (2005). Different emotional reactions to different groups: A sociofunctional threat-based approach to "prejudice." Journal of Personality and Social Psychology, 88, 770-789. doi:10.1037/0022-3514.88.5.770

Davidson, R. J. (1992). Emotion and affective style: Hemispheric substrates. Psychological Science, 3, 39-43. doi:10.1111/j.14679280.1992.tb00254.x

Davidson, R. J., Ekman, P., Saron, C. D., Senulis, J. A., \& Friesen, W. V. (1990). Approach/withdrawal and cerebral asymmetry: Emotional expression and brain physiology. Journal of Personality and Social Psychology, 58, 330-341. doi:10.1037/0022-3514.58.2.330

Denzler, M., Förster, J., \& Liberman, N. (2009). How goal-fulfillment decreases aggression. Journal of Experimental Social Psychology, 45, 90-100. doi:10.1016/j.jesp.2008.08.021

DeWall, C. N., \& Anderson, C. A. (2011). The general aggression model. In M. Mikulincer \& P. R. Shaver (Eds.), Understanding and reducing aggression, violence, and their consequences (pp. 15-33). Washington, DC: American Psychological Association. doi:10.1037/12346-001

DeWall, C. N., \& Bushman, B. J. (2009). Hot under the collar in a lukewarm environment: Words associated with hot temperature increase aggressive thoughts and hostile perceptions. Journal of Experimental Social Psychology, 45, 1045-1047. doi:10.1016/j.jesp.2009.05.003
DeWall, C. N., Finkel, E. J., Lambert, N. M., Slotter, E. B., Bodenhausen, G. V., Pond, R. S., Jr., \& Fincham, F. D. (2011). The voodoo doll task: Introducing and validating a novel method for studying aggression. Manuscript in preparation, University of Kentucky.

DeWall, C. N., Twenge, J. M., Gitter, S. A., \& Baumeister, R. F. (2009). It's the thought that counts: The role of hostile cognition in shaping aggressive responses to social exclusion. Journal of Personality and Social Psychology, 96, 45-59. doi:10.1037/a0013196

Diener, E., Smith, H., \& Fujita, F. (1995). The personality structure of affect. Journal of Personality and Social Psychology, 69, 130-141. doi:10.1037/0022-3514.69.1.130

Ekman, P., \& Friesen, W. V. (1975). Unmasking the face: A guide to recognizing emotions from facial clues. Englewood Cliffs, NJ: Prentice Hall

Faulkner, J., Schaller, M., Park, J. H., \& Duncan, L. A. (2004). Evolved disease avoidance processes and contemporary xenophobic attitudes. Group Processes \& Intergroup Relations, 7, 333-353. doi:10.1177/ 1368430204046142

Fincham, F. D., Cui, M., Braithwaite, S. R., \& Pasley, K. (2008). Attitudes towards intimate partner violence in dating relationships. Psychological Assessment, 20, 260-269. doi:10.1037/1040-3590.20.3.260

Fry, D. P. (2007). Beyond war: The human potential for peace. New York, NY: Oxford University Press.

Giancola, P. R., \& Chermack, S. T. (1998). Construct validity of laboratory aggression paradigms: A response to Tedeschi and Quigley (1996). Aggression and Violent Behavior, 3, 237-253. doi:10.1016/S13591789(97)00004-9

Giancola, P. R., \& Parrott, D. J. (2008). Further evidence for the construct validity of laboratory aggression paradigms. Aggressive Behavior, 34, 214-229. doi:10.1002/ab.20235

Giancola, P., \& Zeichner, A. (1995). Construct validity of a competitive reaction-time aggression paradigm. Aggressive Behavior, 21, 199-204. doi:10.1002/1098-2337(1995)21:3<199::AID-AB2480210303>3.0 . $\mathrm{CO} ; 2-\mathrm{Q}$

Haidt, J., McCauley, C., \& Rozin, P. (1994). Individual differences in sensitivity to disgust: A scale sampling seven domains of disgust elicitors. Personality and Individual Differences, 16, 701-713. doi:10.1016/ 0191-8869(94)90212-7

Haidt, J., Rozin, P., McCauley, C., \& Imada, S. (1997). Body, psyche, and culture: The relationship between disgust and morality. Psychology and Developing Societies, 9, 107-131. doi:10.1177/097133369700900105

Harmon-Jones, E. (2003). Anger and the behavioral approach system. Personality and Individual Differences, 35, 995-1005. doi:10.1016/ S0191-8869(02)00313-6

Harmon-Jones, E., Harmon-Jones, C., Abramson, L., \& Peterson, C. K (2009). PANAS positive activation is associated with anger. Emotion, 9 , 183-196. doi:10.1037/a0014959

Harmon-Jones, E., \& Peterson, C. K. (2008). Effect of trait and state approach motivation on aggression. Journal of Research in Personality, 42, 1381-1385. doi:10.1016/j.jrp.2008.05.001

Harmon-Jones, E., \& Peterson, C. K. (2009). Supine body position reduces neural response to anger evocation. Psychological Science, 20, 12091210. doi:10.1111/j.1467-9280.2009.02416.x

Hoyle, R. H. (1995). Structural equation modeling: Concepts, issues, and applications. Thousand Oaks, CA: Sage.

Inbar, Y., Pizarro, D. A., Knobe, J., \& Bloom, P. (2009). Disgust sensitivity predicts intuitive disapproval of gays. Emotion, 9, 435-439. doi: $10.1037 / \mathrm{a} 0015960$

Jones, A., \& Fitness, J. (2008). Moral hypervigilance: The influence of disgust sensitivity on the moral domain. Emotion, 8, 613-627. doi: $10.1037 / \mathrm{a} 0013435$

Kurzban, R., \& Leary, M. R. (2001). Evolutionary origins of stigmatization: The functions of social exclusion. Psychological Bulletin, 127, 187-208. doi:10.1037/0033-2909.127.2.187 
Levenson, R. W. (1992). Autonomic nervous system differences among emotions. Psychological Science, 3, 23-27. doi:10.1111/j.14679280.1992.tb00251.x

Mortensen, C. R., Becker, D. V., Ackerman, J. M., Neuberg, S. L., \& Kenrick, D. T. (2010). Infection breeds reticence: The effects of disease salience on self-perceptions of personality and behavioral avoidance tendencies. Psychological Science, 21, 440-447. doi:10.1177/ 0956797610361706

Navarrete, C. D., \& Fessler, D. M. T. (2006). Disease avoidance and ethnocentrism: The effects of disease vulnerability and disgust sensitivity on intergroup attitudes. Evolution and Human Behavior, 27, 270282. doi:10.1016/j.evolhumbehav.2005.12.001

Nezlek, J. B. (2001). Multilevel random coefficient analyses of event and interval contingent data in social and personality psychology research. Personality and Social Psychology Bulletin, 27, 771-785. doi:10.1177/ 0146167201277001

Nezlek, J. B. (2007). A multilevel framework for understanding relationships among traits, states, situations, and behaviors. European Journal of Personality, 21, 789-810. doi:10.1002/per.640

Olatunji, B. O., Haidt, J., McKay, D., \& David, B. (2008). Core, animal reminder, and contamination disgust: Three kinds of disgust with distinct personality, behavioral, physiological, and clinical correlates. Journal of Research in Personality, 42, 1243-1259. doi:10.1016/j.jrp.2008.03.009

Olatunji, B. O., Lohr, J. M., Willems, J. L., \& Sawchuk, C. N. (2006). Expectancy bias for disgust and emotional responding in contamination related obsessive-compulsive disorder. Anxiety, Stress \& Coping, 19, 383-396. doi:10.1080/10615800601055964

Olatunji, B. O., Sawchuk, C. N., Lohr, J. M., \& de Jong, P. J. (2004). Disgust domains in the prediction of contamination fear. Behaviour Research and Therapy, 42, 93-104. doi:10.1016/S00057967(03)00102-5

Park, J. H., Faulkner, J., \& Schaller, M. (2003). Evolved disease-avoidance processes and contemporary anti-social behavior: Prejudicial attitudes towards people with disabilities. Journal of Nonverbal Behavior, 27, 65-87. doi:10.1023/A:1023910408854

Profet, M. (1992). Pregnancy sickness as adaptation: A deterrent to maternal ingestion of teratogens. In J. Barkow, L. Cosmides, \& J. Tooby (Eds.), The adapted mind (pp. 327-365). New York, NY: Oxford University Press.

Pronin, E., Wegner, D. M., McCarthy, K., \& Rodriguez, S. (2006). Everyday magical powers: The role of apparent mental causation in the overestimation of personal influence. Journal of Personality and Social Psychology, 91, 218-231. doi:10.1037/0022-3514.91.2.218

Raudenbush, S. W., \& Bryk, A. S. (2002). Hierarchical linear models (2nd ed.). Thousand Oaks, CA: Sage.

Raudenbush, S. W., Bryk, A. S., Cheong, Y. F., \& Congdon, R. T. (2000).
HLM (Version 6.8) [Computer software]. Lincolnwood, IL: Scientific Software International.

Rotton, J. (1979). The air pollution experience and physical aggression. Journal of Applied Social Psychology, 9, 397-412. doi:10.1111/j.15591816.1979.tb02714.x

Rozin, P., \& Fallon, A. (1987). A perspective on disgust. Psychological Review, 94, 23-41. doi:10.1037/0033-295X.94.1.23

Rozin, P., Haidt, J., \& McCauley, C. R. (2008). Disgust. In M. Lewis, J. M. Haviland-Jones, \& L. F. Barrett (Eds.), Handbook of emotions (3rd ed., pp. 757-776). New York: Guilford Press.

Schaller, M. (2006). Parasites, behavioral defenses, and the social psychological mechanisms through which cultures are evoked. Psychological Inquiry, 17, 96-137.

Schaller, M., \& Duncan, L. A. (2007). The behavioral immune system: Its evolution and social psychological implications. In J. P. Forgas, M. G. Haselton, \& W. von Hippel (Eds.), Evolution and the social mind: Evolutionary psychology and social cognition (pp. 293-307). New York, NY: Psychology Press.

Smits, D. J. M., \& Kuppens, P. (2005). The relations between anger, coping with anger, and aggression, and the BIS/BAS system. Personality and Individual Differences, 39, 783-793. doi:10.1016/j.paid.2005.02.023

Taylor, S. P. (1967). Aggressive behavior and physiological arousal as a function of provocation and the tendency to inhibit aggression. Journal of Personality, 35, 297-310. doi:10.1111/j.1467-6494.1967.tb01430.x

Tooby, J. (1982). Pathogens, polymorphism, and the evolution of sex. Journal of Theoretical Biology, 97, 557-576. doi:10.1016/00225193(82)90358-7

Twenge, J. M., Baumeister, R. F., Tice, D. M., \& Stucke, T. S. (2001). If you can't join them, beat them: Effects of social exclusion on aggressive behavior. Journal of Personality and Social Psychology, 81, 1058-1069. doi:10.1037/0022-3514.81.6.1058

Tybur, J. M., Lieberman, D., \& Griskevicius, V. (2009). Microbes, mating, and morality: Individual differences in three functional domains of disgust. Journal of Personality and Social Psychology, 97, 103-122. doi:10.1037/a0015474

Warburton, W. A., Williams, K. D., \& Cairns, D. R. (2006). When ostracism leads to aggression: The moderating effects of control deprivation. Journal of Experimental Social Psychology, 42, 213-220. doi: 10.1016/j.jesp.2005.03.005

Wilkowski, B. M., \& Meier, B. P. (2010). Bring it on: Angry facial expressions potentiate approach-motivated motor behavior. Journal of Personality and Social Psychology, 98, 201-210. doi:10.1037/a0017992

Received June 2, 2010 Revision received February 21, 2011 Accepted April 20, 2011 